\title{
CIVILIZAÇÃO NA ENCRUZILHADA: GLOBALIZAÇÃO PERVERSA, DESIGUALDADES SOCIOESPACIAIS E PANDEMIA
}

\section{Civilization at a crossroads: perverse globalization, socio-spatial inequality and pandemic}

\author{
Márcio Cataia \\ Professor Livre Docente do Departamento de Geografia, IG/UNICAMP \\ Pesquisador do $\mathrm{CNPq}$ \\ cataia@unicamp.br
}

Artigo enviado para publicação em 04/05/2020 e aceito em 06/05/2020

DOI: $10.12957 /$ tamoios.2020.50742

\begin{abstract}
Resumo
Interrogo o período da globalização a partir das iniquidades que tem promovido em todo o mundo, com especial atenção para a periferia do sistema, e o seu ocaso com a chegada da pandemia do Covid19. Esse exame coloca foco nas variáveis-chave da globalização, a unicidade da técnica, a convergência dos momentos, a cognoscibilidade do planeta e a existência de um motor único, o lucro. Essa força motriz é analisada ao colocar a competitividade no centro da reflexão. Os agentes da globalização são aludidos para a compreensão de suas estratégias de ação na defesa da globalização perversa. Teoricamente tomo a pandemia como um evento geográfico, porque ele é datado e geografizado. Essa geografização é referida à escala de origem, de onde parte o vetor difusor, e à escala de impacto, o lugar, onde o vetor se horizontaliza para promover situações geográficas. As desigualdades sócioespaciais estão no núcleo do debate sobre as situações geográficas, pois o evento Covid19 se horizontaliza sobre espaços herdados impactados pelo neoliberalismo, o que torna a situação única e dramática. Nesse período de transição para uma outra globalização, o Estado da globalização perversa e o Estado de Direito são politicamente confrontados.
\end{abstract}

Palavras-chave: globalização perversa; desigualdades sócioespaciais; pandemia Covid19; Estado de insegurança.

\begin{abstract}
Globalization has been promoting inequality throughout the globe, especially in the outskirts of the system. In this paper I question globalization regarding the outbreak of COVID-19 pandemic. This study focuses on the key variables of globalization: the unicity of techniques, the convergence of moments, the knowability of the planet and the existence of a single motor of history, which is profit. Competitiveness is put in the center of debate in order to analyze this driving force. The agents of globalization are mentioned so as to understand its strategies to maintain a perverse globalization. In a theoretical basis, the pandemic will be regarded as a geographic event as it is marked in time and space. The geographization of the pandemic refers to its scale of origin - where the vector is originated - and its scale of impact - where there has been a horizontal spread of the vector, producing geographic situations. Socio-spatial inequalities are in the center of the debate concerning geographic situations due to the fact that COVID-19 spreads across spaces affected by neoliberalism, which causes the situation to be unique and severe. In this transition to another globalization, the State of the perverse globalization and the legal state are politically opposed.
\end{abstract}

Keywords: perverse globalization; socio-spatial inequality; COVID-19 pandemic; State of insecurity. 
Não devemos esquecer que o que torna os adeptos da globalização tão perigosos é que eles sabem que perderam

Bruno Latour

\section{Introdução}

A pandemia, sem ainda ter sido decretada como tal pela Organização Mundial de Saúde, começou a ter contornos mais nítidos no Brasil na segunda semana de março. Até então, sabia-se de uma epidemia localizada em Wuhan (China), mas eram apenas ecos de informações, nada que tivesse atingido fisicamente o sistema de fluxos aéreos e marítimos e seus pontos nodais globais, portos e aeroportos. Contudo, em pouquíssimo tempo, um evento local, epidêmico, transformou-se em evento global, pandêmico, por meio da velocidade das redes físicas. O primeiro mapa da pandemia que tive contato mostrava rotas de difusão do coronavírus pelo Hemisfério Norte, partindo do leste chinês, sobrevoava toda Ásia, pousava na Europa - especialmente na "megalópole", a Banane Bleu - e chegava nos EUA, especialmente em Nova Iorque.

Já decretada, a pandemia começava a se aproximar do Sul, ou aproximar o Norte do Sul, no que, talvez, seja a primeira e última pandemia da globalização. No dia 12 de março de 2020, a Universidade Estadual de Campinas tomou a decisão de suspender atividades administrativas e acadêmicas presenciais - exceto as hospitalares - até o dia 29 de março, um domingo, quiçá na esperança de que a segunda-feira, dia 30, trouxesse a normalidade. $\mathrm{O}$ normal e o patológico foram colocados à nossa frente sob o signo da crise, um conceito ônibus, no qual cabe de tudo dentro, especialmente o medo de "fisicamente isolados" enfrentar o desconhecido.

Também começava, como não poderia deixar de ser em um ambiente de pesquisa científica, a procura por explicações sobre o vírus desconhecido. Socialmente interessava saber como achatar a curva de contaminação para não sobrecarregar o sistema de saúde, e, particularmente, saber como cada pessoa poderia ficar de fora da curva de contaminação, sobretudo, idosos e portadores de doenças crônicas - de fato, a lógica contábil, inicialmente, avassalou as interpretações. A grande mídia continuou com seu papel de difusão das informações, inclusive dando voz a interpretações alucinadas do poder global, que buscava colocar o vírus como inimigo e trabalhadores da área médica como heróis agindo sob a glória de uma guerra. A busca de culpados e bodes expiatórios, 
envolvidas em teorias conspiratórias, buscava criar um campo geopolítico para aprisionar o debate. Só precisávamos achar o culpado a quem punir.

Especialistas foram chamados pelo poder a dar voz ao vírus. Fomos informados que preventivamente alguns cuidados ou medidas deveriam ser observadas, como lavar as mãos com água potável corrente e sabão, algo simples para a classe média; usar álcool gel em tudo, trivial para a classe média; manter isolamento físico - na mídia, equivocadamente, chamado de social -, uma medida que não é simples, mas é acessível, e talvez até prazerosa, para a classe média que dispõe de metros quadrados em casa e pode se esquivar do transporte coletivo. Todas essas ações solicitadas no cotidiano, na vida cotidiana, implicam o lugar de cada um nas classes sociais e no espaço, especialmente nas grandes cidades e suas imensas periferias. A conclusão geográfica é evidente e amplamente conhecida: a existência é condicionada pelo lugar que ocupamos nos grupos sociais e nas classes sociais, mas também e, sobretudo, pelo lugar ocupado no espaço.

É nesse sentido que a pandemia é um evento geográfico (SANTOS, 1996), ou seja, é o veículo de um processo datado e geografizado. Datado porque pode ser periodizado, isto é, tem uma duração, com um começo, passando por um ápice até atingir a domesticação do vírus, que pode significar o seu fim ou, mais provável, a sua convivência em conflito permanente com a sociedade. Ela evidentemente é geografizada, porque apresenta um lugar a partir do qual se difunde - sua escala de origem - e, ao atingir outros lugares e se realizar - sua escala de impacto -, precipita situações específicas (SANTOS, 1996; CATAIA \& RIBEIRO, 2017), tanto mais distintas quanto são as diferenças e desigualdades entre os lugares. Uma situação envolve um lugar, um pedaço do espaço, mais as ações que sobre ele se dão, desde as ações locais até aquelas de dimensões globais. Por isso, um mesmo evento se dando sobre lugares diferentes e desiguais, produz combinações diversas e sua realização transita entre a minoração de implicações ou sua potencialização.

No mundo todo, mas principalmente na periferia do sistema, as situações geográficas têm nas desigualdades socioespaciais seu relevo de maior destaque. A configuração do território, especialmente a das cidades, é uma condicionante fundamental da vida cotidiana. Tanto na prevenção, quanto no uso dos equipamentos públicos de saúde, a distribuição dos equipamentos de exercício da cidadania reproduz a desigualdade entre áreas de rarefação e áreas de densidade, com as conhecidas consequências tétricas. 
As desigualdades socioespaciais estão no centro da encruzilhada que vivemos no período atual agravadas pela pandemia.

A pandemia teria precipitado o fim de um período, o período da globalização perversa? O período que a sucederá não mostra todos os seus contornos, mas nesse momento essa é uma pergunta inescapável, por essa razão, centro minha análise no período atual.

\section{A globalização como período e perversidade}

A reflexão é sobre o tempo presente, o período da globalização, esse pedaço de tempo que pode ser individualizado a partir de variáveis-chave ou fatores determinantes. É chamado de período da globalização porque suas variáveis instalam-se por toda parte e, direta ou indiretamente, influenciam em tudo. Essa globalização, iniciada na década de 1970, é uma globalização perversa porque o mundo tornou-se um inferno para a grande maioria das pessoas, a pobreza foi transformada em sistema e a concentração de riqueza, com a produção de ultra-ricos, não tem paralelo em qualquer momento da história do capitalismo. Conforme Milton Santos (2000) suas variáveis-chave são (i) a unicidade da técnica, (ii) a convergência dos momentos, (iii) a cognoscibilidade do planeta e (iv) a existência de um motor único da história, representado pela mais-valia globalizada.

A unicidade técnica é referida à aplicação em escala planetária de meios para transformação e uso de materiais, objetos, máquinas e serviços segundo parâmetros únicos sob a égide das grandes empresas do mercado internacional. O tráfego aéreo, terrestre e marítimo globalizado seria impensável sem essa unicidade técnica, tanto quanto os meios de pagamentos e a circulação de dinheiro realizados por conglomerados financeiros. Trata-se de um uso da técnica para a fluidez, para a celeridade, principalmente a velocidade das técnicas virtualizadas nas novas tecnologias da comunicação e da informação, fundamentais para a convergência dos momentos.

A convergência dos momentos refere-se ao tempo real ou interdependência dos eventos, que autoriza a usar um mesmo momento, um mesmo instante a partir de diversos lugares, e todos esses lugares são conectados por um único lugar. Os eventos possuem uma escala de origem ou de força, onde as variáveis envolvidas no evento são produzidas e uma escala de realização, onde ocorre a sua incidência, que se faz ao mesmo tempo em diversos lugares contíguos ou distantes. É uma conecção coesa e eficaz, utilizada em 
nome de uma fluidez informacional e voltada para um melhor conhecimento das coisas, das pessoas e do planeta.

O conhecimento profundo e extensivo do planeta, como nunca se pode fazer antes, é o que Milton Santos (2000) chama de cognoscibilidade do planeta. O desenvolvimento da ciência e da técnica permite não só conhecer os objetos existentes e desvendar o funcionamento da Terra em detalhes, mas também conceber e criar novos materiais e objetos em laboratórios, revalorizando objetos técnicos, sistemas e lugares. O que têm consequências profundas para a mais-valia global, porque a seletividade do capital pode ser mais pontual.

A força motriz única, ou o ímpeto incessante pela mais-valia, tem que ver com o ritmo concertado pela competitividade globalizada. A competitividade, palavra-chave da globalização na busca ininterrupta pela eficácia, leva sempre a uma fuga para frente buscando mais inovação para mais dinheiro, uma corrida destrutiva que, agora sabemos empiricamente, não é criativa, porque é incapaz de incorporar o que não é hegemônico. E não é criativa também porque não há competitividade global sem a legitimação do pensamento único, expresso nas ideologias individualista e consumista - que seriam impossíveis sem o controle dos espíritos.

Essas quatro variáveis-chaves constituem-se em uma arquitetura sistêmica que permitiu, com a ação decisiva de agentes poderosos do Estado e do mercado hegemônico, a eclosão de um mercado global perverso, por que fundado sobre princípios segundo os quais a competição em todos os níveis da vida em sociedade representa um avanço civilizatório. O princípio corporativo da competição transborda do mercado e atinge praticamente todos os âmbitos da vida.

Contudo, a competitividade global é o fundamento da destruição de um sem número de economias endógenas, com diminuição das rendas, desemprego e precarização do trabalho. O entendimento da natureza como cultura, também leva a falar em destruição de espaços vividos consoante um trabalho territorializado, ou seja, enraizado segundo princípios próprios e controlados por solidariedades domésticas. Em diálogo com o conceito de evento, Ribeiro \& Silva (2004) afirmam que nos lugares atingidos por impulsos globais a relação mais direta dos grupos sociais com o seu meio, isto é, a territorialidade é quebrada e as mediações passam a ser externas promovendo uma perda de controle técnico e político dos rumos internos. Ribeiro \& Silva (2004) denominam de impulsos globais os vetores que condensam informação e inovação, fazendo emergir formas de agir de natureza sistêmica e corporativa. Os impulsos globais reproduzem 
movimentos de subordinação socioeconômica, criando novas configurações hierárquicas e aprofundando outras já existentes.

Os processos de modernização, exigentes de vetores informacionais inovadores concretizados por objetos técnicos e processos os mais modernos, sempre precedidos e acompanhados pelo tríptico ideologia/finança/mídia - são carregados de intencionalidades indizíveis. Essa globalização é concomitante com a ascensão do neoliberalismo e seu capitalismo de catástrofe (KLEIN, 2008), porque a combinação de seus fatores-chave agindo sobre os lugares, especialmente nas formações socioespaciais periféricas, têm levado a segregações, exclusões e, enfim, à instalação da pobreza como estrutura do sistema econômico-político.

Quem são seus atores privilegiados? Se os eventos possuem uma escala de origem, um lugar onde são produzidos, há personas (RIBEIRO \& SILVA, 2004) em sua origem com força de imposição.

Os agentes hegemônicos da globalização são grandes empresas transnacionais, sobretudo, do sistema financeiro e das agências de notícias - controladoras das grandes mídias -, agências de risco, organismos internacionais como FMI (Fundo Monetário Internacional) e Banco Mundial e um punhado de Estados que têm hegemonia geopolítica regional e mundial. Essas são forças capazes de produzir eventos em escala planetária. Com o poder que cada um desses agentes reuniu individualmente, mas, sobretudo, em alianças, impuseram aos lugares e a alguns territórios nacionais inteiros - não sem conflitos -, o "seu" mercado (hegemônico) por meio da difusão de uma ideologia e de um sistema produtivo. A ideologia que sempre precede o sistema produtivo estruturalmente comprometido com a pobreza de muitos e a produção de ultra-ricos, é aquela da angelização do mercado hegemônico e demonização do Estado, mas demonização de um Estado em específico, do Estado de segurança social.

\section{Sistema de ações: Estado e as classes da globalização como agentes}

Com a globalização perversa assistimos à formação de uma elite em escala mundial, que não obedece ao clássico processo de formação das classes sociais (pela posse direta dos meios de produção), mas nem por isso deixa de ter traços identificáveis de ações comuns. Apresenta uma originalidade primordial: a existência e grupos sociais cujos interesses ligam-se diretamente à economia global. Três segmentos são referenciados: econômico, midiático e politico. A formação de alianças de interesses entre 
esses segmentos, para um pensamento e ação global, é constitutiva, sendo a fração financeira a amplificada da economia. Essa elite financeira da globalização tem uma ideologia e uma estratégia. A primeira é representada pela competitividade como mecanismo de regulação da globalização, e a segunda é referida à recusa em se submeter ao poder político. (NAÏR \& MORIN, 1997)

De fato, é um poder oligárquico: dezenas de grandes redes financeiras, industriais e midiáticas, tendo as "informacionais" o maior destaca dos dias atuais, mundialmente conhecidas pelo acrônico GAFA (Google, Aplle, Facebook, Amazon), que muitos solicitam incorporar a letra $\mathrm{M}$ de Microsoft. O poder de decisão das grandes empresas está fora do controle dos Estados e fora dos processos de representação e legitimação políticas. Como afirmam Naïr e Morin (1997) legalidade e ilegalidade das atividades, para essas empresas, são relativas. Agem à sombra buscando escapar às normas do direito, fixadores de limites, das regras e das sanções, especialmente são alérgicas ao pagamento de impostos. Seus quadros são seus dirigentes diretos e milhares de "colaboradores" espalhados pelo mundo. A título de classificação seus representantes vão desde os quadros da tecnociência, passando pelas tecnoburocracias (nacional e internacional), por diretores de bancos e grandes transnacionais, especuladores financeiros, patrões e altos funcionários das empresas de mídia, traficantes internacionais e os "bobos da corte" como estrelas de televisão, desportistas de grandes marcas, estrelas da alta-costura, chefs de cozinha midiáticos, lideres de seitas religiosas rentáveis. Enfim, trata-se de um fenômeno elitista em escala global.

Para Saskia Sassen (2010) essas elites da globalização formam uma nova classe social. Não estão mais e apenas centradas na inter-relação entre Estado-nação e classes nacionais, mas sua mobilidade se dá dentro de empresas e instituições de caráter transnacional. Ainda que ela não seja composta só por uma elite, porque também incluiria os imigrantes da globalização que não têm para onde ir - e não podem voltar para seus países e regiões de origem - e acabam por habitar grandes assentamentos sem nação, elas se distinguem por grupos profissionais e por, pelo menos, três conjuntos. Primeiro pela força motriz que alimenta a emergência desse domínio transfronteiriço: o ímpeto para o lucro. Em segundo lugar, a posição sistêmica dessa classe entre a esfera nacional e internacional, ou seja, são classes que transitam internacionalmente. Em terceiro lugar, a hipermobilidade não pode ser confundida com o trabalho dessas classes. Este encontrase ancorado certos lugares que possuem as virtualidades exigidas pelas profissões da globalização, e estas seriam as cidades globais. Ou, em outros termos, nos espaços da 
$\overline{\text { globalização, onde as variáveis-chave do período encontram sinergia para sua realização }}$ mais eficaz e plena.

A lógica da competição, cada vez mais, confunde-se com práticas predatórias. Lógica competitiva e prática predatória, conformariam o que Saskia Sassen (2016) chama de "formação predatória", envolvendo sistematicamente elites predatórias, financeirização de todos os setores de atividades, privatizações e uso dos recursos do Estado - oriundos dos impostos de quem os paga - para a proteção da predação de recursos naturais e sociais.

Quanto ao Estado, a grande tarefa dos agentes da globalização perversa, em consonância com o Consenso de Washington, foi de reduzir gastos que a sociedade assume para garantir, tanto quanto possível, para cada indivíduo um emprego, um salário digno e acesso à saúde e educação. Essa faina foi acompanhada do discurso de exaltação das virtudes das iniciativas individuais e do empreendedorismo contra a tirania e arcaísmo do Estado de bem-estar social (RANCIÈRE, 2020). Empregos e salários dignos, saúde e educação são as seguranças que não foram dadas, mas retiradas, para oferecer ao mercado a segurança de que este tanto solicita e sem a qual, afirmam os mercadores, não haveriam investimentos para o crescimento econômico. Ao Estado, que possui o uso legítimo da força, coube a função de proteção do mercado hegemônico, oligopolizado e monopolizado (WALLERSTEIN, 2002), ou nas palavras de Dardot \& Laval (2016) tratou-se do amparo ao Direito Privado. Segundo os princípios da globalização perversa, Estado forte sim, mas em sua defesa.

Portanto, quando um editorial do jornal Finantial Times - bíblia do neoliberalismo - defende mais Estado para o combate do Covid19 ou quando o presidente do Banco Mundial propõe maior intervenção estatal para salvar vidas é preciso muita precaução, porque defendem a intervenção do Estado em benefício do mercado hegemônico - o mesmo que promoveu a pobreza estrutural desse período -, uma escora que objetiva salvar os grandes capitais dessa crise que se abateu sobre a economia mundial. Como afirma Raffestin (1993), o mapa do poder financeiro é lacunar, ele não se interessa pela totalidade do território quando se trata de agir para semear capitais; ele somente é um mapa completo quando se trata de arrecadar, de colher o dinheiro. Ou seja, ele é seletivo. 


\section{Ação concreta dos agentes e horizontalização do evento}

Os eventos se estendem uns sobre os outros nos lugares, participando, portanto, uns dos outros e criando o movimento de continuidade temporal e solidariedade espacial. Assim, quando a pandemia se tornou um evento dimensões globais, já encontrou espaços em crise, porque essa crise é estrutural e global, faz parte do período. Como afirmava Santos (2000), o período é a crise. O vírus chegou e encontrou espaços fragilizados para a defesa da vida, com manifestações particulares mais ou menos dramáticas neste ou naquele país e regiões - as situações geográficas. O vírus encontrou um mundo preparado para a fluidez, para a celeridade de uma economia internacional voraz por mais dinheiro. O caminho estava preparado para a difusão do vírus para além das fronteiras nacionais tornadas anacrônicas pelo globalismo -, em velocidade inaudita e em linhas retas; não foi uma viagem labiríntica.

A globalização perversa, chamada por Octávio Ianni (2000) de globalismo, por defender tratar-se de um sistema, transformou o mundo em um inferno para a grande maioria das pessoas. Essa figura de um mundo tornado inóspito ocorre a muitos autores, ainda que em outras traduções, outras linguagens e diferentes perspectivas teóricas. Um crítico ácido do período atual, traduzido em suas formulações com o conceito de neoliberalismo, Mbembe (2020), assim interpreta a questão central que a pandemia enseja: "O sistema capitalista é baseado na distribuição desigual da oportunidade de viver e de morrer. Essa lógica do sacrifício sempre esteve no coração do neoliberalismo, que deveríamos chamar de necroliberalismo. Esse sistema sempre operou com a ideia de que alguém vale mais do que os outros. Quem não tem valor pode ser descartado".

A posse do novo ministro da saúde do Brasil, senhor Nelson Teich, trouxe à tona uma lúgubre opinião sua gravada em um evento em abril de 2019. Nela o tema é investimento. Dêmos ao ministro a palavra: "Como é que seria o ideal, na minha opinião, sobre como estruturar uma proposta. A primeira coisa que você tem que mapear é qual a necessidade da população. E a segunda é quanto dinheiro você tem. [...] como você tem um dinheiro limitado, você vai ter de fazer escolhas. Então você vai ter de definir onde você vai investir. Então, sei lá, eu tenho uma pessoa que é mais idosa, que tem uma doença crônica avançada, ela teve uma complicação. Para ela melhorar, eu vou gastar praticamente o mesmo dinheiro que eu vou gastar para investir num adolescente que está com um problema. O mesmo dinheiro que eu vou investir, é igual. Só que essa pessoa é 
um adolescente que vai ter a vida inteira pela frente e o outro é uma pessoa idosa que pode estar no final da vida. Qual vai ser a escolha? ${ }^{1}$

Explicita-se a vida como valor de troca e o dinheiro é colocado no centro de tudo, o que abre espaço para todas as formas de barbárie pela qual deixam morrer os descartáveis (Santos, 2000). Como afirma Srecko Horvat ${ }^{2}$ “o diabo não é o vírus, mas o neoliberalismo".

A situação é agravada pelo fato de que um evento e dimensões devastadoras atingiu lugares onde em eventos anteriores foram produzidos e vivenciados pela ultraelites e duravam para chegar até os pobres (PINÇON; PINÇON-CHARLOT, 2014). Os lugares são definidos pela combinação qualitativa e quantitativa de vetores - materiais e imateriais - que acolhe (Santos, 1996), mais o grau de centrifugismo ou centripetismo de suas atividades. Esta é uma razão, talvez central, de a cidade mais modernizada do país, São Paulo, ter o maior número de infectados do Brasil. Seu grau de centrifugismo a faz ser um nódulo importante de redes globalizadas, por isso a contaminação chegou primeiro e sua horizontalização é mais rápida, por isso, mais crítica. $\mathrm{O}$ achatamento da curva de contaminação é uma combinação positiva entre a horizontalização do evento (COVID19) e lugar; já o pico da curva de contaminação é a incapacidade de resposta positiva do lugar ao mesmo evento. Positivo ou negativo, o lugar se reconfigura para responder ao evento $^{3}$. A estatística (curva, achatamento, pico) é um recurso abstrato das situações concretas dos lugares.

Admitindo-se a definição dos lugares e eventos e sua importância analítica como exposto, o território nacional poderá ser definido como uma unidade política da diversidade de lugares. Essa diversidade possui muitas expressões, mas a que toma o maior relevo é a desigualdade socioespacial, centro de gravidade das situações concretas em face ao evento. Sem querer esgotar as possibilidades de arranjos sistêmicos entre os vetores, podemos observar essas desigualdades orientadas segundo dois pares dialéticos, densidade e rarefação e fluidez e viscosidade. Do primeiro par, destacamos as distintas capacidades de isolamento com salubridade existentes nos mais diversos lugares, especialmente nas grandes cidades e suas periferias pobres e, a capacidade de atendimento oferecido pela rede hospitalar, já que o espaço herdado apresenta imensas áreas de rarefação desses instrumentos. Do segundo par, ressaltamos a capacidade de difusão da pandemia em razão dos sistemas de transporte presentes nos lugares - internos e em conecção com o exterior -, ou seja, quanto maior a fluidez do território, mais apto é o espaço para fazer circular, daí ser lícito afirmar que a fluidez capilariza a difusão do vírus. 
Por fim, mas não menos importante, intervém a ação política que anima os pares dialéticos e deles retira condicionantes. A interlocução eficaz da sociedade e do mercado (social e hegemônico) com o Estado: muitos grupos sociais em muitos espaços recusaram, outros não tiveram condições materiais, sobretudo, de aceitar ações preventivas de isolamento físico e muitas empresas (desde pequenas até grandes) mantiveram seu funcionamento, o que sustentou certo fluxo de pessoas e mercadorias - vetores da pandemia. E do lado do Estado, alguns governos, "necrogovernos" que insistem na defesa intransigente do mercado, seguem negando a pandemia, o que agrava a situação.

Assim, as respostas que os lugares dão ao evento Covid-19 são distintas, mas sobretudo, desiguais, pela desigual “...distribuição da oportunidade de viver e de morrer" (MBEMBE, 2020). O território nacional já se tornou mais desigual.

\title{
Globalização como pharmakon
}

Estes são aspectos dominantes do processo de globalização com a chegada da pandemia, entretanto, a análise solicita, para estar completa, pensar um projeto, isto é, a partir do que temos, pensar um outro futuro.

\begin{abstract}
"O mundo é formado pelo que já existe (aqui, ali, em toda parte), mas pelo que pode efetivamente existir (aqui, ali, em toda parte) [...] É somente a partir dessa constatação, fundada na história real do nosso tempo, que se torna possível retomar, de maneira concreta, a ideia de utopia e de projeto. Este será o resultado da conjugação de dois tipos de valores fundamentais, essenciais, fundadores do homem, válidos em qualquer tempo e lugar, como a liberdade, a dignidade, a felicidade; de outro lado, surgem os valores contingentes, devidos à história do presente, isto é, à história atual. A densidade e a factibilidade história do projeto, hoje dependem da maneira como empreendemos sua combinação" (Santos, 2000, p. 160-161).
\end{abstract}

Esse é um quadro fundamental para a compreensão do presente momento. Como as alternativas ao futuro não são criadas na mesma velocidade que as urgências sociais e o como futuro sempre está em aberto, é a partir do que temos que podemos pensar alternativas de um devir digno em defesa de sociedades igualitárias, democráticas e plurais.

Há uma avaliação comum, no campo político das esquerdas em particular e dos progressistas em geral, de que não será possível, depois dessa pandemia, continuar com o projeto capitalista dessa globalização perversa. Com efeito, estamos convivendo com amplas incertezas, mas há uma certeza como bem afirmou Roberto Savianno (2020), “a fraqueza está em se crer invencível”" . Assim, o ponto central dessa transição é a patente 
fragilidade do poder da globalização perversa, especialmente expressos em suas dimensões econômica e ideológica.

Mas, "não devemos esquecer que o que torna os adeptos da globalização tão perigosos é que eles sabem que perderam" (LATOUR, 2020). Os agentes da globalização vão lutar em sua defesa; há 500 anos os capitalistas não perdiam. O Estado de Direito de Exceção (ANTUNES, 2018) já vem sendo praticado e é uma figura à qual os defensores da globalização perversa estão se aferrando. Daí a defesa do Estado de Direito, instituição com legitimidade de imposição da força para o controle do mercado hegemônico. Instituição do diálogo internacional e eficaz na construção de uma outra globalização e, sobretudo, única instituição que se deixa democratizar - o mercado é surdo para a desigualdade.

O combate à pandemia não pode servir de pretexto para um aprofundamento das políticas neoliberais. Entretanto, agora, no meio da pandemia, os agentes da globalização, com o suporte nacional das elites das classes da globalização (SASSEN, 2010), para não perder os dedos aceitam entregar os anéis. Do centro do sistema surgem discursos sobre o fortalecimento do Estado e impostos sobre grandes fortunas e no Brasil ouvimos ecos sobre a importância da filantropia e benevolência em momentos de crise. As duas posições, que não são excludentes, mas se interpenetram, objetivam mudar alguma coisa para dar sobrevida às mesmas desigualdades socioespaciais que tornaram a pobreza estrutural. Por isso, o mercado hegemônico - que tem poder de imposição dos imperativos da globalização neoliberal - deve estar sob controle social, pois as desigualdades socioespaciais só podem ser enfrentadas com políticas democráticas e igualitárias. Por isso, a importância da identificação concreta da estrutura e sistêmica da globalização perversa, bem como seus agentes, práticas e estratégias. A compreensão do processo permite ampliar as ações coletivas, em face da civilização ${ }^{5}$ que, mais uma vez, encontrase em uma encruzilhada.

A globalização é um pharmakon - "ideia de um medicamento que opera ao mesmo tempo como remédio e como veneno" (MBEMBE, 2016) -, do mesmo modo que suas variáveis foram usadas e abusadas para produzir uma globalização perversa, elas também podem ser usadas para uma outra globalização. "Daí a relevância da política, arte de pensar as mudanças e de criar as condições para torna-las efetivas [...] Esse é o debate central" (Santos, 2000). 


\section{Notas}

1 - Transcrição disponível em https://noticias.uol.com.br/colunas/rubensvalente/2020/04/16/mandetta-coronavirus-saude.htm

2 - Disponível em https://shifter.sapo.pt/2020/03/srecko-horvat-coronavirus/

3 - As imagens de barracas de campanha (das forças armadas usadas como hospitais nos momentos de pico da pandemia) sendo desmontadas depois de passado o pico da contaminação nos lugares, não tem outra função senão iludir os espíritos. Nada voltará a ser como antes, nem os eventos ulteriores, nem os lugares reconfigurados extensa e profundamente.

4 - No original: "la faiblesse, c'est de se croire invincible."

5 - Inspirado no título "Civilização na encruzilhada", livro de Radovan Richta, referido na bibliografia.

\section{Bibliografia}

ANTUNES, Ricardo. O privilégio da servidão. O novo proletariado de serviços na era digital. São Paulo: Boitempo, 2018.

CATAIA, Márcio; Ribeiro, Luis Henrique Leandro. Análise de situações geográficas: notas sobre metodologia de pesquisa em geografia. Revista da Anpege, v. 11, n. 15, p. 9=30, jul, $2017 . \quad$ Disponível em http://ojs.ufgd.edu.br/index.php/anpege/article/view/6445. Consulta: 04/05/2020.

DARDOT, Pierre; LAVAL, Christian. A nova razão do mundo. Ensaio sobre a sociedade neoliberal. São Paulo: Boitempo, 2016 (2009).

KLEIN, Naomi. Doutrina do choque. A ascensão do capitalismo de desastre. Rio de Janeiro: Nova Fronteira, 2008.

IANNI, Octávio. Enigmas da modernidade-mundo. Rio de Janeiro: Civilização Brasileira, 2000.

LATOUR, Bruno. Imaginar gestos que barrem o retorno da produção pré-crise. AOCMedia, domingo 29 março de 2020. Disponível em http://www.brunolatour.fr/sites/default/files/downloads/P-202-AOC-03-20-PORTUGAIS_2.pdf

MBEMBE, Achille. Pandemia democratizou poder de matar. Entrevista publicada no Jornal Zero Hora em 30/03/2020. Disponível em https://gauchazh.clicrbs.com.br/politica/noticia/2020/03/pandemia-democratizou-poderde-matar-diz-autor-da-teoria-da-necropolitica-ck8fpqew2000e01ob8utoadx0.html. Consulta: 04/05/2020.

MBEMBE, Achille. Politiques de l'inimitié. Paris: La Découverte, 2018 (1ª Ed. 2016). NAÏR, Sami; MORIN, Edgar. Uma política de civilização. Lisboa: Instituto Piaget, 1997.

PINÇON, Michel; PINÇON-CHARLOT, Monique. La violence des riches. Chronique d'une immense casse sociale. Paris: La Decouverte, 2014.

RAFFESTIN, Claude. Por uma geografia do poder. São Paulo: Ática, 1993 (1 ${ }^{\text {a }}$ Ed. 1983).

RANCIÈRE, Jacques. La esencia del Estado contenporáneo. Lobo Suelto, 19/04/2020. Disponível em http://lobosuelto.com/la-esencia-del-estado-contemporaneo-1-jacquesranciere/ 
RIBEIRO, Ana Clara Torres; SILVA, Cátia Antonia da. Impulsos globais e espaço urbano: sobre o novo economicismo. In Ribeiro, Ana Clara Torres Ribeiro (org.). El rostro urbano de América Latina. Buenos Aires: Clacso, 2004, p. 347-368.

RICHTA, Radovan. La civilización en la encrucijada. Implicaciones sociales y humanas de la revolución cientificotécnica. México, DF: Siglo Veintiuno, 1970 (1 ${ }^{\text {a }}$ Ed. 1966).

SANTOS, Milton. Por uma outra globalização. Do pensamento único à consciência universal. São Paulo/Rio de Janeiro: Record, 2000.

SANTOS, Milton. A natureza do espaço. Tempo e técnica, razão e emoção. São Paulo: Hucitec, 1996.

SASSEN, Saskia. Expulsões. Brutalidade e complexidade na economia global. Paz e Terra: Rio de Janeiro, São Paulo, 2016 ( $1^{\text {a }}$ Ed. 2014.

SASSEN, Saskia. Sociologia da globalização. Porto Alegre: Artmed, 2010 (1ª Ed. 2007)

SAVIANO, Roberto. La faiblesse, c'est de se croire invincible. Le monde, 12 avril 2020. Disponível em https://www.lemonde.fr/idees/article/2020/04/12/roberto-saviano-lafaiblesse-c-est-de-se-croire-invincible_6036361_3232.html. Consulta: 04/05/2020.

WALLERSTEIN, Immanuel. O fim do mundo como o concebemos. Ciência social para o século XXI. Rio de Janeiro: Revan, 2002 (1 ${ }^{\text {a }}$ Ed. 2001). 